Revista Iberoamericana, Vol. LXVII, Núm. 197, Octubre-Diciembre 2001, 755-766

\title{
POLÍTICAS CULTURALES EN LOS PROCESOS DE INTEGRACIÓN REGIONAL: EL SECTOR EDITORIAL EN EL MERCOSUR
}

POR

María Eugenia Mudrovcic

Michigan State University

A diferencia de otros tratados de integración regional, el Mercosur aspira a la creación de un mercado común que trascienda aspectos exclusivamente económicos y jurídicos, e incorpore el área de la cultura al proceso supranacional de integración. En este trabajo me propongo analizar las políticas culturales emanadas del Mercosur a partir de dos preguntas iniciales: ¿cuál es el nuevo modelo que impone al sector editorial este proceso de integración que combina la globalización con la regionalización? y ¿de qué manera se alteran los circuitos tradicionales del mercado del libro?

Como una forma de profundizar el acercamiento argentino-brasileño iniciado en 1986, el Mercosur se constituye en zona de libre comercio a partir del Tratado de Asunción (1991) rubricado por Argentina, Brasil, Paraguay y Uruguay. ${ }^{1}$

Con la implementación de este regionalismo abierto, el Mercosur logra sumar como bloque un mercado de 186 millones de habitantes y un Producto Nacional Bruto de 436,000 millones de dólares, de los cuales Brasil representa aproximadamente el 78\%; Argentina, el 18\%; y Paraguay y Uruguay alrededor del 2\%, respectivamente. A diferencia de los modelos de integración ensayados en los años '50 y '60, el modelo vigente se caracteriza por la apertura no controlada de los mercados internos a la economía mundial. Tres procesos organizan esta tendencia liberadora: la desgravación acelerada que tiene como meta abarcar todos los sectores, la reducción del papel del Estado proteccionista que tradicionalmente controlaba asignaciones, preferencias arancelarias y remisión de utilidades, y la privatización masiva de empresas y servicios públicos. Según los apóstoles del libre comercio, estas estrategias integrativas resultarán en un aceleramiento del desarrollo de las economías regionales, disminuyendo costos y elevando utilidades.

\footnotetext{
${ }^{1}$ Dos objetivos centrales pautan la consolidación del proceso integrativo: lograr, por un lado, "la libre circulación de bienes, servicios y factores productivos entre los países miembros, a través, entre otros, de la eliminación de los derechos aduaneros y de las restricciones arancelarias a la circulación de mercaderías y de cualquier equivalente” y establecer, por otro, “un arancel externo común y la adopción de una política comercial común con relación a terceros”. Dirigido por el Consejo del Mercado Común y un cuerpo ejecutivo constituído por comisiones técnicas, el Mercosur contempla la incorporación de otros Estados al proceso de integración. En 1996 ingresaron Chile y Bolivia como miembros asociados, y en 1995 se acordó la creación de un espacio de diálogo y cooperación con la Comunidad Europea para debatir cuestiones relacionadas con estándares industriales, certificación, aduanas, estadísticas y propiedad intelectual.
} 
¿Qué lugar ocupa la cultura en esta nueva etapa de regionalización económica, articulada a un nivel transnacional y pensada en función del modelo de acumulación difusa del capital? En contraste con acuerdos como el Tratado del Libre Comercio, el Mercosur percibe el área cultural como parte dinámica del proceso de regionalización, creando a partir del Protocolo de Integración Cultural (Fortaleza, 1996) un espacio institucional para la discusión y armonización de políticas culturales de los Estados miembros. En líneas generales, el documento-base en materia cultural reconoce la diversidad de las identidades, favorece el intercambio cultural y contempla como prioridad la formación de recursos humanos. ${ }^{2}$ La elaboración de políticas culturales dentro de este marco conceptual queda en manos de Comisiones Técnicas, responsables, por un lado, de trabajar en la convergencia de legislaciones específicas sobre incentivos fiscales a la cultura, derechos de autor y propiedad intelectual; y de tratar de salvar, por otro, los desajustes que se dan entre "el concepto de cultura patrimonialista, que prevalece en las dependencias estatales de cultura, y un enfoque comercial destinado al tratamiento de los productos industriales" (Álvarez 185).

Esta agenda de cambios en cultura manifiesta la voluntad de inserción del Mercosur en el proceso de recomposición internacional de mercados y de industrias culturales donde la tendencia a la mercantilización de bienes simbólicos aparece como un efecto "natural" de las políticas neoliberales. ${ }^{3}$ Ya se sabe: si en los '70 “todo era política,” a partir de los '90 la economía del mercado pasa a ser el organizador transnacional de la cultura. Al cambiar las reglas de circulación y gestión cultural con miras a lograr una rápida escalada en la rentabilidad y la eficiencia, el nuevo modelo de desarrollo económico cambia también el lugar que ocupa la cultura en la sociedad. "The basic processes, organization, and agents of cultural production and dissemination are changing” confirma García Canclini. “[T]he direct producers (artisans, artists, designers) are no longer the principal creators and administrators of the processes of social significacion. The role of tradicional promoters of cultural activity (states, social movements) has diminished, while that of organisms linked to the expanding modes of capitalist development (financial institutions, cultural foundations, and chains of art galleries related to finance capital or high-tech industries) is on the rise" ("Cultural Reconversion” 33).

Previsiblemente, en el marco económico y político consolidado por el Mercosur, los capitales multinacionales fueron los que más rápidamente avanzaron en la carrera por la expansión de los mercados editoriales. ${ }^{4}$ En este sector, España es, como también en los

\footnotetext{
${ }^{2}$ Para un análisis de los antecedentes, contenidos y proyecciones del Protocolo de Integración Cultural, consúltese Saravia (1997) y Álvarez y Reyes (1997).

${ }^{3}$ Para Rafael Roncagliolo, la volundad de participar en la economía global que manifiesta el nuevo modelo de integración (a los ojos de Roncagliolo, un "integrar-se” panamericanista) desplaza el modelo previo de integración que se basaba más bien en la unión defensiva y sindical entre países pobres (o sea, un “integrar-nos” latinoamericanista) (1996, 41; 1999, 57).

${ }^{4}$ En los cuatro países del Mercosur, el libro está exento del pago de aranceles de importación y del impuesto al valor agregado (en Latinoamérica solamente Chile y Bolivia aplican IVA a la producción editorial). Sin embargo, las diferencias cambiarias y los desajustes en materia de incentivos a la exportación editorial altera la circulación y la estructura productiva del libro en la región. La sobrevaluación del dólar en Argentina, por ejemplo, lleva a la estructura productiva a trasladarse a
} 
sectores de telecomunicaciones, financiero y de infraestructura, el inversor líder en la región. ${ }^{5}$ La lista es extensa pero elocuente. El Grupo catalán Planeta, integrado por los sellos Seix Barral, Espasa Calpe, Ariel, Temas de Hoy, Destino, Deusto y Planeta, tiene filiales en Argentina, Brasil y Uruguay y desde el año pasado lidera, con la adquisición de la editorial argentina Emecé, el que se considera el mercado editorial más competitivo de lengua española en Latinoamérica. ${ }^{6}$ El grupo Santillana, conformado por los sellos Alfaguara, Aguilar, Altea y Taurus, opera en Argentina desde 1963, en Uruguay desde 1993 y acaba de comprar la editorial brasileña Moderna, una de las principales editoriales de educación, con más de 1.500 títulos en su catálogo y llave a un mercado de 44 millones de estudiantes que presentan un atractivo adicional después de haber sido reglamentada en 1999 la enseñanza del español como segunda lengua. En 1997, Javier Vergara Editor de Argentina fue comprada por Ediciones B (ex-Bruguera) que pertenece al Grupo Z, también de capitales mayoritariamente españoles. Y este año (2001) la división editorial de Bertelsmann (ahora asociada para la edición de libros en español en una joint venture al 50\% con Mondadori) adquirió a través de la editorial Plaza y Janés, integrada por los sellos Plaza, Lumen, Debolsillo, Galaxia Gutenberg, Grijalbo y Debate, el 100\% de la editorial argentina Sudamericana, pilar en la consagración del boom latinoamericano de los años ’60.

Chile, Brasil y Uruguay donde los costos de impresión son menores, y una vez impresas, las ediciones vuelven a reentrar para aprovechar los reintegros a las exportaciones de la que gozan los libros en el país.

${ }^{5}$ Bonet y de Gregorio atribuyen el "impresionante crecimiento" que indicaron a partir de los '90 las inversiones directas españolas en América Latina, tanto al mejoramiento de las condiciones macroeconómicas de la región, como a la fase expansiva internacional de ciertos sectores que siguió a la integración de España a la CEE. Y agregan: "El atractivo de América Latina como destino de futuras inversiones es claro: un gran potencial de crecimiento económico y demográfico, unos sectores con capacidad de aprendizaje y posibilidad de mejora de la gestión, unos mercados no agotados, y una manifiesta necesidad de capital inversor. Y el atractivo es aún mayor para España, debido a la afinidad cultural y lingüística, y a la situación de puente entre la Unión Europea, el Mercosur y el resto de los países de la región” (90).

${ }^{6}$ Fundada en Buenos Aires en 1939, Emecé fue, junto a Sudamericana y Losada, uno de los tres pilares editoriales sobre el que se sostuvo el mítico mercado del libro argentino. A lo largo de 60 años de operaciones, logró ocupar en el campo cultural una posición atípica que le permitió liderar la venta de lo mejor de dos mundos posibles: por un lado, el prestigio que le aseguró a los ojos del polo "autonómo" del mercado poseer en exclusividad los derechos sobre la obra de Jorge Luis Borges y Adolfo Bioy Casares; y por otro, el éxito de ventas que logró gracias a la traducción de autores como Sidney Sheldon, Robin Cook o Wilbur Smith cuyos best sellers le permitieron dominar una franja importante del polo "heterónomo" o comercial de la ficción internacional en castellano. De esta forma, el fondo editorial de Emecé, con un volumen de publicaciones que alcanza los diez títulos mensuales y un total aproximado de 120 lanzamientos por año, ofrecía a Planeta no sólo un catálogo diversificado y extenso, sino también el acceso al liderazgo del mercado editorial más rentable en lengua española de América Latina. Los 15 millones de dólares que desembolsó Planeta en lo que El País calificó “uno de los negocios editoriales más importantes del 2000”, representaban poco menos del $20 \%$ del total facturado por el grupo catalán el año anterior, una cifra sin duda magra si se tiene en cuenta el capital simbólico que ponía en juego semejante transacción. 
“In Publishing, Bigger is Better” sentenciaba en 1998 una nota del New York Times donde se celebra la decisión del grupo alemán Bertelsmann de comprar Randhom House (Bibb). En el actual sistema de diseminación cultural regido por criterios empresariales, la lógica de acumulación es siempre inflacionaria: los grandes grupos editoriales tienen más presupuesto para la publicidad, más poder de comercialización, y una red más eficaz de prensa a su servicio. A su vez, la concentración del poder económico y financiero y la lucha por lograr la máxima rentabilidad afecta también las estructuras de comercialización. Son pocas las corporaciones que sólo se expanden horizontalmente, muchas más son las que lo hacen verticalmente, tratando de apropiarse no sólo de los circuitos de producción sino también de los de distribución. Es lo que técnicamente se llama habilidad de explotar la "sinergía” entre compañías aglutinadas bajo una misma corporación. Un ejemplo: el Grupo Santillana acaba de comprar la cadena argentina de librerías Fausto para evitar lo que le ocurrió a Planeta con las librerías Yenny y El Ateneo: estas dos cadenas, propiedad del petrolero Gruneisen, presionaron al grupo catalán para conseguir mejores precios de tapa y cuando no lo obtuvieron implementaron mecanismos de castigo relegando sus títulos en las mesas de exhibición (Sánchez, "La novela del libro argentino” 4).

El sistema global, edificado sobre la creencia de que el mercado constituye una suerte de democracia del consumo, es paradójicamente un sistema no-competitivo en todos los sentidos económicos del término. Para reducir riesgos y aumentar ganancias, la dinámica globalizante no impulsa la competencia sino más bien la absorción de la competencia. Las redes del capital global son, por ello, intrínsecamente incestuosas. Cuando en 1997 la revista Variety confeccionó una lista de los mayores conglomerados de medios, caracterizó la tendencia al cruce corporativo característico de la "merger mania” como "a complex web of interrelationships that will make you dizzy” (31). Poco más o menos, a esta misma conclusión también llega McChesney: “the global media market more closely resembles a cartel than it does the competitive marketplace found in economics textbooks” (13). Los holdings en el sector editorial apuntan a controlar nichos específicos de mercado. En el caso de libros de bolsillo, por ejemplo, el grupo Santillana se asoció con Ediciones B y Planeta con Bertelsmann para lanzar dos líneas de bolsillo “que en Argentina -se queja un distribuidor- van a costar 8 pesos, mientras en España cuestan 4” (Sánchez, "La novela del libro argentino" 3).

La política editorial de los conglomerados responde a ciertos criterios más o menos estándares: cada título debe generar ganancias y ninguno debe subsidiar a otros; se buscan tiradas de 5.000+ ejemplares (cuando las tiradas promedio de las editoriales familiares rondaban los 3.000 ejemplares), se espera un margen de ganancia del $12 \%$ (cuando lo estandard oscila entre el 3 y 4\%), y se tiende a acelerar el flujo de capitales evitando financiar el sistema de consignaciones vigente para librerías y otros circuitos de comercialización. Las presiones en torno al aumento de las ganancias son tan fuertes que una de las salidas es la expansión sobre la base de nuevas adquisiciones y una vez en marcha este proceso de concentración, los grupos editoriales llegan a adquirir tales dimensiones que sólo pueden ser absorbidos por otros conglomerados. "Expand or die" es la consigna-mantra de Rupert Murdoch.

Otra regla de oro de los conglomerados es "pensar en forma global pero actuar en forma local.” ¿Qué significa esta fórmula para el sector editorial? Sin excepción, los grupos transnacionales operan a través de una extensa red de filiales distribuidas por toda 
Latinoamérica. Alfaguara, por ejemplo, con 17 filiales, abarca al igual que Planeta una suma de mercados nacionales que supera en número cualquier zona de libre comercio constituida por los procesos de integración regional. Sin embargo, estas filiales actúan como estructuras flexibles y autónomas, sin conexión entre unas y otras, y por lo tanto están lejos de conformar circuitos de comunicación y distribución para que se den las bases de "un espacio cultural latinoamericano". En la medida en que el capital se globaliza, los mercados del libro se segmentan y se provincializan. El alto grado de riesgo que implica la integración horizontal de mercados locales excluye esta opción del mapa de intenciones que trazan los grupos transnacionales editoriales. "Planeta se instala en Uruguay -aclara Mario Ale, representante del grupo catalán- para editar autores nacionales. La transcendencia de eso es una puerta abierta para los autores, por la cual nosotros trabajamos [pero] nosotros no vendemos la fantasía de que el libro irá a otros mercados” (Díaz 11). Por otro lado, la producción local de los grupos editoriales atiende fundamentalmente a autores consagrados, los únicos que ofrecen un retorno seguro. La edición de autores desconocidos, de difícil venta y alto riesgo, que son sin embargo los que garantizan el ciclo de renovación simbólica a todo mercado editorial, sigue en manos de editoriales locales. Esta desigualdad en la distribución del riesgo, agravada por la pérdida de "grandes autores" y el traslado de los derechos de autor a favor de los grupos editoriales y de los agentes literarios extranjeros, desacelera el dinamismo simbólico de los mercados nacionales y desalienta la inversión de los agentes locales. ${ }^{7}$

La reconfiguración de las prácticas económicas y culturales influye además en la toma de decisiones editoriales que, en manos de herméticas élites tecnológico-económicas, muestra un movimiento de preferencia hacia los títulos de retorno garantizado. Se privilegian así publicaciones de temática new-age, libros de cocina, gift-books, o librosblockbusters como Yo soy el Diego (2000), las memorias de Diego Maradona que Planeta lanzó en un tiraje sin precedente de 350.0000 ejemplares, y que llegó a vender 220.000 copias en una semana. Otro efecto de lo mismo es el signo conservador de la oferta editorial. "Nowadays -afirma André Schiffrin- the figure settled upon is usually decided according to what the author's previous book has sold. This has necessarily led to a marked conservatism, both aesthetic and political, in what is chosen: a new idea, by definition, has no track record" (106). De ahí que los mercados del libro cuyos ciclos de consagración se vinculan a la vanguardia, como es el caso argentino, presentan menos incentivos para los conglomerados. Esta contradicción entre lógicas económicas y lógicas estéticas se traduce en la percepción desolada que Gloria Rodrigué de Sudamericana ofrece del mercado argentino: "Nuestros socios alemanes preguntan quiénes son nuestros grandes escritores, y la verdad es que no los hay. El último fue Osvaldo Soriano” (Sánchez, "La novela del libro argentino" 4).

\footnotetext{
${ }^{7}$ Pablo Herari, responsable de Ediciones Trilce, lamenta los términos conflictivos de la convivencia entre editoriales uruguayas y grupos transnacionales: "los autores se sintieron seducidos ante el ofrecimiento de estas editoriales multinacionales y me parece que eso no está mal. El problema es cuando se dejan atraer por cantos de sirena. Eso sí duele porque nosotros hemos realizado muchos esfuerzos por autores 'sacrificando' trabajo, esfuerzo económico, y luego aparecen editoriales con un nombre extranjero, se sienten atraídos y van a editar allí. Digo que es un canto de sirenas porque editar en una transnacional no significa que serán distribuidos fuera de fronteras” (Díaz 11).
} 
Tradicionalmente la industria editorial respondía a una economía vinculada a los niveles de escolarización, al tamaño y poder adquisitivo de los mercados, a la identidad lingüística y a los hábitos de los consumidores. Ahora su eje se desplaza hacia un nuevo modelo regido por la innovación permanente tanto en el polo de la producción como en el del consumo. El resultado: la fuerte segmentación de los mercados del libro. La mayoría de los catálogos tiende a abandonar el concepto de fondo editorial sobre el que se edificaron las editoriales familiares y a reemplazarlo por el sistema de "novedades". Las principales editoriales que una década atrás admitían a lo sumo un promedio de diez lanzamientos por mes, hoy están publicando entre quince y treinta títulos nuevos, como es el caso del Grupo Zeta. Esta aceleración y diseminación de la oferta editorial tiende a inhibir el circuito clásico de consolidación literaria: “[E]l sistema económico está siendo atravesado por una enorme variedad de productos orientados a cubrir los millones de nichos de mercados" que, lejos de constituir un escenario competitivo, ha llegado a convertirse en “un comercio de tipo 'bélico' donde el objetivo es lograr el dominio del mercado, mediante una enorme diversificación de los productos con marcas distintas y atendiendo a públicos diferentes y hasta contradictorios” (Rama 58-9).

Para acelerar los consumos, el sector editorial tampoco elude los mecanismos de la obsolescencia planificada, con una clara tendencia a reducir stocks por la velocidad que se imprime a los ciclos de renovación y a la rápida rotación de capitales invertidos. Se trata de un mercado altamente segmentado que propicia la coexistencia de pocos best-sellers de grandes tirajes y ventas, junto a la proliferación de un número cada vez más grande de títulos de menores ventas y tirajes. “A la concentración económica correspondió una fuerte segmentación del mercado — confirma Ricardo Sabanes, director de Planeta-Argentina. Esto significa que se venden menos ejemplares de cada libro pero se publica más” (Sánchez, "La novela del libro argentino" 5).

La tensión en torno a las lógicas basadas en derechos de autor o en el copyright constituye otro de los frentes en que se disputa la imposición del nuevo modelo de las industrias culturales. La actual dinámica de acumulación está obligando a la industria editorial a funcionar no como una industria cultural sino como una industria de producto cuyo modelo más cercano lo ofrece la industria fonográfica y cinematográfica, o sea, "industrias basadas en la venta de derechos de reproducción sustentadas en estructuras mundiales de control a través de sociedades de autores o cámaras empresariales” (Rama 66). De acuerdo con los criterios seguidos por la Organización Mundial de la Propiedad Intelectual (OMPI), la legislación latinoamericana considera autores sólo a las personas físicas mientras que el sistema de copyright o propiedad intelectual del modelo anglosajón (que incluye patentes, marcas y derechos de autor) permite registrar los derechos a favor del productor. El primer paso para hacer converger las legislaciones de derecho autorial con las de propiedad intelectual lo ha dado, de manera previsible dada su participación en el Tratado de Libre Comercio, México, con las modificaciones implementadas en 1991 a la Ley Federal de Derechos de Autor. ${ }^{8}$ En el marco del Mercosur, Brasil ya cuenta desde 1998 con una nueva ley de propiedad intelectual, mientras Uruguay y Argentina están próximos a sancionar sus respectivas leyes sobre derechos de autor. En líneas generales,

${ }^{8}$ Sobre los cambios y efectos de la nueva legislación mexicana en torno a la propiedad intelectual pueden consultarse Nivón y de María y Campos (257-59). 
los dos grandes cambios que incorpora la nueva legislación son: 1) la creación del “derecho de edición” como “un derecho de propiedad intelectual diferente y autónomo del derecho de los autores de obras publicadas" y 2) la fuerte penalización a "quienes reproduzcan en forma facsimilar un libro o partes de él sin autorización de su autor y su editor” (Kolesnicov). Este desplazamiento poco sutil en favor del modelo anglosajón de propiedad intelectual no parece sin embargo suficiente para evitar la sanción global. Anualmente los países que no cumplen con las normas de protección a la propiedad intelectual enunciadas en el acuerdo TRIPS (trade-related intellectual property) de la Organización Mundial del Comercio son incluidos por Estados Unidos en la lista de “vigilancia” o “vigilancia prioritaria”. Este año, Paraguay aparece junto a Ucrania y China en la última categoría y registra los índices de piratería más altos a escala mundial, a su vez Argentina y Uruguay —cuya producción ilegal en el 2000 representó pérdidas estimadas en 39,7 millones a la industria norteamericana—, se ubican en la lista de "vigilancia". Brasil, único país del bloque con una ley sancionada de propiedad intelectual, tampoco escapa a las críticas del Departamento de Comercio de Estados Unidos que califica de "proteccionistas" algunos de sus tramos por considerarlos "hechos para crear empleos para brasileños”. El reporte es utilizado como un medio de presión a aquellos Estados que "no velan por el respeto pleno de las normas que tutelan la propiedad intelectual" (“Uruguay al borde...”).

En el nuevo paisaje trazado por la globalización, la industria editorial, históricamente regulada, enmarcada por los derechos de autor, dependiente del sistema de stocks y con ciclos de rotación y renovación relativamente lentos, comienza a entrar en contradicción con el nuevo modelo editorial, desregulado, desterritorializado, encuadrado dentro de la propiedad intelectual, de baja dependencia en stocks y de mayor integración entre producción y consumo. Un síntoma de la asimetría estructural que manifiesta hoy la industria editorial se ve en el uso de la fotocopia y en la proliferación de ediciones piratas. Dos ejemplos descriptivos: el lanzamiento de La fiesta del Chivo (Alfaguara) de Mario Vargas Llosa llegó a competir con cinco ediciones piratas y El pez en el agua (Seix Barral) circuló antes en ediciones ilegales que en la original. Colombia, cuya industria editorial está amparada por una de las legislaciones más proteccionistas de la región —la ley del libro exime de impuestos por veinte años a editores residentes en el país y el Estado se compromete a comprar el $20 \%$ de las ediciones para bibliotecas - alberga uno de los centros de impresión y exportación de ediciones ilegales que le cuesta a la industria editorial española alrededor de US\$500 millones anuales en concepto de derechos de autor. Pero esta manifestación de la economía informal o este "imperio de la delincuencia" — si se prefiere usar el rótulo acuñado por el Centro Español de Derechos Reprográficos (CEDRO) — no va a desaparecer en la medida en que los precios y la velocidad que ofrecen los sistemas actuales de edición y comercialización no respondan a la rapidez con que se renueva el conocimiento y al nivel de ingresos de los mercados latinoamericanos. "Hoy el sector pasa globalmente a ser de primera necesidad indirecta, y en tal sentido la demanda es tal, que ella misma reclama la oferta en tiempo y forma, la cual pasa a ser por fotocopia ilegal, en la medida que las nuevas técnicas de impresión, y el pasaje del offset al tonner así lo permiten” (Rama 65). En los años '60, “un libro costaba menos que un kilo de pan, menos que un atado de cigarrillos, menos que una botella de vino común” (Rodríguez 93), 
ahora el precio en Latinoamérica de una novela como Cien años de soledad cuesta, según una investigación realizada por la agencia de prensa DPA, un promedio de US\$13,6, lo que representa casi el 15\% del salario mínimo. En Alemania, el mismo libro sale US\$ 9,35 y representa un 3\% del salario mínimo (Rama 107). Con índices de analfabetismo funcional que rondan el 60\%, el descuido de los Estados latinoamericanos en materia de políticas culturales afecta a su vez el desarrollo de los mercados editoriales que buscan maximizar la rentabilidad en el menor tiempo posible. El avance "a lo ancho" que caracteriza el estilo de comercialización de las corporaciones no constituye sin embargo el único centro de la crisis cultural: “¿Podemos criticar al inversor —se pregunta Guillermo Schavelson-que quiere el mayor rendimiento posible? Las empresas hacen negocios, los Estados crean lectores. Pedirle lo segundo a las primeras es el error de nuestra concepción tercermundista del Estado liberal” (4).

De acuerdo con la UNESCO, el Estado moderno debe garantizar tanto el "derecho a la cultura” como el derecho a la educación y al trabajo. En otras palabras, el acceso a la cultura no se da en forma lineal sin que estén dadas las condiciones materiales para la satisfacción del derecho social y económico de los ciudadanos. ¿Cuál es la respuesta de Estados comprometidos en procesos de integración para tratar de equilibrar las asimetrías culturales que la apertura económica exaspera? En el Mercosur, el fomento al patrocinio de terceros (fundaciones, empresas y autores) parece indicar una tendencia creciente a desviar hacia el sector privado el financiamiento de la cultura. Tanto en la 2da. Reunión Especializada de Cultura (Asunción, 1995) como en el Protocolo de Integración Cultural (Fortaleza, 1996), se acordó estimular la creación de incentivos fiscales para el sector privado que favorezca la producción, coproducción y ejecución de proyectos considerados de interés cultural. Chile y Brasil ya cuentan con leyes de mecenazgo y Argentina está en vías de aprobar también una ley de desgravación impositiva para incentivar la participación privada en la promoción cultural. La ley Rouanet implementada en 1995 en reemplazo a la ley Sarney, alentó en Brasil una escalada de aportes a la cultura que de 14 millones en 1994 alcanzó los 270 millones en 1998, creando alrededor de 160 empleos por cada millón invertido. Para Fernando Henrique Cardoso, la monumental retrospectiva de los 500 años del Descubrimiento fue un indicador concluyente del “éxito” de la nueva legislación. Con los 30 millones de dólares que donaron la fundación Arte Viva, vinculada al grupo O Globo, Telefónica, Repsol y el Banco Santander, entre otros, se hizo, según celebró la prensa, “posible lo imposible” (“España en Río”): fletar un avión para trasladar la gigantesca tela de la "Recuperación de Bahía” de Juan Bautista Maino, reunir las escenas de la batalla de Pernambuco que no habían estado juntas desde el siglo XVII, lograr que más de 40 obras del Prado sean exhibidas en el Museo de Bellas Artes de Río y contar en la inauguración con la visita oficial de los reyes de España, hoy uno de los mayores protagonistas en el proceso brasileño de privatizaciones.

Modelo para el proyecto de ley argentina de mecenazgo, la ley Rouanet establece que los aportes privados sean canalizados por el Fondo Nacional de Cultura, fijando una desgravación del 80\% para donaciones y del 60\% para patrocinios y un premio para aquellas inversiones que favorezcan a los sectores priorizados por el Estado: "la preservación del patrinomio histórico, al igual que el cine, puede desgravar el 100\% del costo en incentivos fiscales, mientras la edición de un libro puede obtener hasta el 40\%” (Sánchez, 
“Esperando al mecenas” 4). Argentina está, sin embargo, lejos de poder imaginar cifras de inversiones comparables: el Estado apenas destina el 0,22\% del presupuesto a la promoción cultural (cuando la UNESCO aconseja llegar al menos al 1\%), y una estimación generosa calcula que la inversión privada sólo alcanza los tres millones anuales. A esto se suma la debilidad del sistema tributario estatal y la falta de una tradición de filantropía corporativa en el país (de 147 empresas líderes sólo tres practican auspicios con cierta continuidad: Telefónica, Banco Velox y Andreani). Otra duda que surge cuando se piensa en el mecenazgo es la variable-censura que entra en juego cuando criterios empresariales interfieren en las relaciones horizontales entre artistas, mercado y público. El caso de Amalia Lacroze de Fortabat, figura-institución de la burguesía industrial argentina, no sólo habla de la curiosa convergencia que se da en la esfera cultural entre gestión estatal y mecenazgo privado, sino también de los condicionamientos que mediatizan la relación de patrocinio privado a la cultura. Actual presidenta del Fondo Nacional de las Artes, organismo de aplicación de la futura ley de mecenazgo, "this cement heiress who is considered a pillar of Argentine society”, la caracterización pertenece al New York Times y es también un punto de referencia dentro del sistema de mecenazgo dada la gestión de la Fundación Fortabat que capitanea. Una gestión, habría que agregar, que en 1998 no eludió la censura cuando decidió impugnar la recomendación del jurado de otorgar a $E l$ anatomista de Federico Andahazi los US\$ 15.000 con que la Fundación Fortabat premia cada dos años a la primera novela de autor argentino. Según el anuncio pagado que circuló en la prensa, Amalia de Fortabat canceló el premio por considerar que la novela de Andahazi - una obra que habla de sexo, poder y censura -“no contribuye a la exaltación de los grandes valores del espíritu humano” (Sims). Lejos de la tentación iluminista, Jorge Balán aventura sin embargo otra hipótesis: “The book exposes the way in which the church ignores, yesterday and today, a reality that is there for everyone to see, and I believe this is what bothered Mrs. Fortabat the most” (Sims). Lo cierto es que debido al escándalo en torno a la novela, las ventas se dispararon y Doubleday llegó a pagar US\$200.000 por los derechos de traducción, una cifra récord nunca antes alcanzada por una obra argentina. En último análisis, antes que del avance oportunista del mercado, el caso de El anatomista habla más bien de cómo los intereses y el techo ideológico del mecenas puede desordenar los circuitos “naturales” de producción, circulación y consumo de bienes simbólicos.

Frente a esta transformación de las sociedades civiles en sociedades-mercado, frente al efecto totalitario de lo que García Canclini llama nuestro "modo neoliberal de globalizarnos” (Consumidores y ciudadanos 18), la pregunta que cabe plantear es: ¿qué hacer para equilibrar los intereses sociales con la agresividad con la que las transnacionales luchan por maximizar su rentabilidad económica? ¿Cuál es el margen de acción de los Estados-nación debilitados por la concentración económica y financiera, con poca o nula capacidad de control social y cultural? En este proceso marcado por la hipercomercialización y la tendencia desregulada y transnacional de la producción y difusión cultural, los Estados-nación pierden fuerza como referentes jurídico-políticos y "cuando uno dice menos Estado — sostiene Bourdieu — hay que saber que esto también quiere decir menos cultura, cultura libre, cultura creadora” (Parentella 4). Sin embargo, a pesar de que la Organización para la Cooperación y el Desarrollo Económico presiona a los gobiernos para eliminar preferencias entre inversores nacionales y extranjeros en "una especie de 
golpe de Estado de las multinacionales” (Estefanía), aún se oyen propuestas que buscan proteger a las industrias culturales. En 1998 los ministros de cultura de veinte naciones se reunieron en Otawa y recomendaron mantener la cultura fuera del control de la Organización Mundial del Comercio. El mismo año, las Naciones Unidas reunidas en Estocolmo aconsejaron también excluir a las industrias culturales de los intercambios comerciales globales. Se diría que los organismos internacionales y las instancias intergubernamentales creadas a partir de los acuerdos de integración regional parecen ahora constituirse en espacios-refugio para la regulación y defensa de la soberanía cultural. Porque, como afirma García Canclini, “no hay razones para pensar que los gobiernos que en los últimos años [...] desmantelaron la infraestructura de apoyo a la cultura, vayan a reconocer las consecuencias funestas que ha tenido sobre la producción endógena la desregulación neoliberal y la mercantilización a ultranza de su espacio cultural. Sólo es posible imaginar que los acuerdos de integración y libre comercio que se gestionan por toda América sirvan para reactivar las industrias culturales si incluyen una política de re-regulación y promoción pública de la cultura latinoamericana” (Consumidores y ciudadanos 130).

Hoy, sin embargo, a diez años de su constitución, el Mercosur languidece jaqueado por la recesión, la devaluación del real, el avance del Área de Libre Comercio de las Américas (ALCA) y el abandono de Argentina del arancel externo común que exacerba rivalidades comerciales y liquida la unión aduanera, convirtiendo al Mercosur en una zona imperfecta de libre comercio. ${ }^{9}$ Más lejos que nunca de la integración horizontal de la cultura en la región, el intervencionismo proteccionista que García Canclini reclama a las “grandes máquinas” - llámense Estados-nación, organismos intergubernamentales o internacionales - no aparece sin embargo contemplado como alternativa en las políticas de convergencia cultural del Mercosur. Más bien, las tres preocupaciones que intermitentemente han ocupado las negociaciones entre los países miembros: la legislación en torno a la propiedad intelectual, la implementación del mecenazgo y la armonización de órganos regionales para propiciar la producción y comercialización ilegal indican que el objetivo del Mercosur en materia cultural podría quedar mejor definido como la construcción de un espacio común ampliado para facilitar la gestión de agentes del sector privado y no, como declaran las Actas de la primera reunión de la Comisión Técnica de Industrias Culturales, "para proteger y promover las respectivas industrias nacionales, en el camino de la construcción de una integración cultural” (“Actas”).

\footnotetext{
${ }^{9}$ Durante los primeros ocho años del Mercosur, el comercio intrazonal aumentó consistentemente, pasando de U\$ 4.7 billones en 1991 a U\$ 18 billones en 1998. A fines de ese año, la retracción de la economía brasileña y la posterior modificación del régimen cambiario provocaron la fuerte alteración de la estructura de precios y competitividad de los países miembros, poniendo en crisis el proceso de integración regional. "El sueño (en realidad, la pesadilla) neoliberal terminó -afirmó entonces Luiz Inacio 'Lula' da Silva. Destruyó nuestros sistemas productivos, multiplicó el desempleo, aumentó la exclusión y con ella tornó más violentas nuestras sociedades... En el pasado, los generales sembraron la rivalidad militar entre nuestros países. En el presente, los tecnócratas cultivan antagonismos económicos intentando, así, el fracaso de sus respectivas políticas económicas”.
} 
“Actas de la primera reunión de la Comisión Técnica de Industrias Culturales”. Buenos Aires, 24 y 25 de abril de 1995.

Álvarez, Gabriel Omar. "Integración regional e industrias culturales en el Mercosur: Situación actual y perspectivas”. Las industrias culturales en la integración latinoamericana. Néstor García Canclini y Carlos Moneta, eds. Buenos Aires: Eudeba, 1999. 165-204.

Álvarez, Marcelo y Nicolás Patricio Reyes. "La agenda de la gestión cultural en el Mercosur”. Mercosur: La dimensión cultural de la integración. Gregorio Recondo, ed. Buenos Aires: Ciccus, 1997. 155-70.

Bibb, Porter. “In Publishing, Bigger is Better”. New York Times (31 March 1998).

Bonet, Lluís y Albert de Gregorio. “La industria cultural española en América Latina”. Las industrias culturales en la integración latinoamericana. Néstor García Canclini y Carlos Moneta, eds. Buenos Aires: Eudeba, 1999. 77-111.

da Silva, Luiz Inacio “Lula”. “El sueño neoliberal terminó.” Clarín (Buenos Aires, 12 agosto 1999).

de María y Mauricio Campos. "Las industrias culturales y de entretenimiento en el marco de las negociaciones del Tratado de Libre Comercio”. La educación y la cultura ante el Tratado de Libre Comercio. Gilberto Guevara Niebla y Néstor García Canclini, eds. México: Nueva Imagen, 1992. 235-98.

Díaz, Nelson. "Una relación que comienza: Editoriales extranjeras, autores nacionales”. El País Cultural (Montevideo, 27 junio 1997): 10-11.

“España en Río: Exposición e inversiones”. La Nación (Buenos Aires, 7 diciembre 2000).

Estefanía, Joaquín. “El AMI, un acuerdo casi clandestino”. El País (Madrid, 29 marzo 1998): 54.

García Canclini, Néstor. “Cultural Reconversion”. On Edge: The Crisis of Contemporary Latin American Culture. George Yúdice, Jean Franco y Juan Flores, eds. Minneapolis: University of Minnesota Press, 1992. 29-43.

Consumidores y ciudadanos. Conflictos multiculturales de la globalización. México: Grijalbo, 1995.

Kolesnicov, Patricia. "La actividad editorial, con más beneficios”. Clarín (8 septiembre 1998).

McChesney, Robert Waterman. “The New Global Media”. The Nation (29 noviembre 1999): 11-15.

Nivón, Eduardo. “Propiedad intelectual y derechos de autor”. La educación y la cultura ante el Tratado de Libre Comercio. Gilberto Guevara Niebla y Néstor García Canclini, eds. México: Nueva Imagen, 1992. 299-309.

Parentella, Lima. “Libros para el pueblo”. Radar Libros (Buenos Aires, 26 de marzo de 2000): 4.

Peers, Martin. “The Global 50”. Variety (25-31 de agosto de 1997): 31.

Rama, Claudio. La economía del libro en el Mercosur. Montevideo: Arca, 1994.

Rodríguez, Horacio. “Eudeba y la crisis universitaria argentina”. Mundo Nuevo 5 (1966): 91-94. 
Roncagliolo, Rafael. “La integración audiovisual en América Latina: Estados, empresas y productores independientes”. Culturas en globalización. América Latina-EuropaEstados Unidos: Libre comercio e integración. Néstor García Canclini, ed. México: Editorial Nueva Sociedad, 1996. 41-54.

"Las industrias culturales en la videosfera latinoamericana". Las industrias culturales en la integración latinoamericana. Néstor García Canclini y Carlos Moneta, eds. Buenos Aires: Eudeba, 1999. 57-73.

Sánchez, Matilde. "La novela del libro argentino: Los nuevos dueños de la máquina cultural”. Zona-Clarín (23 abril 2000): 3-5.

“Esperando al mecenas: ¿Quién banca a los artistas?” Zona-Clarín (22 octubre 2000): 3-5.

Saravia, Enrique. “El Mercosur Cultural: Una agenda para el futuro”. Mercosur: La dimensión cultural de la integración. Gregorio Recondo, ed. Buenos Aires: Ciccus, 1997. 137-54.

Schavelzon, Guillermo. "Por un mercado largo". Zona-Clarín (23 abril 2000): 4.

Schiffrin, André. The Business of Books. Londres: Verso, 2000.

Sims, Calvin. "Sex and the Argentines: The Anatomy of a Scandal". New York Times (Nueva York, 17 mayo 1997).

“Uruguay al borde de sanción por piratería”. El País (Montevideo, 4 mayo 2001).

Yúdice, George. "La industria de la música en la integración América Latina-Estados Unidos”. Las industrias culturales en la integración latinoamericana. Néstor García Canclini y Carlos Moneta, eds. Buenos Aires: Eudeba, 1999. 115-61. 